\title{
Social Security, Retirement and Economic Growth
}

\author{
Kuo-Ting Hua \\ Department of Economics, National Chi Nan University, Taiwan \\ Email: kthua@ncnu.edu.tw
}

How to cite this paper: Hua, K.-T. (2018) Social Security, Retirement and Economic Growth. Theoretical Economics Letters, 8, 3481-3491.

https://doi.org/10.4236/tel.2018.815214

Received: October 15, 2018

Accepted: December 2, 2018

Published: December 5, 2018

Copyright $\odot 2018$ by author and Scientific Research Publishing Inc.

This work is licensed under the Creative

Commons Attribution International

License (CC BY 4.0).

http://creativecommons.org/licenses/by/4.0/

\begin{abstract}
Population aging alters decisions of retirement and intergenerational transfers simultaneously. With the consideration of both decisions, this paper investigates the economic impacts of population aging in an Overlapping-Generation (OLG) model under social security coverage. Results show that the economy grows slower with voluntarily increased elderly labor supply than otherwise. Ignoring the interactions between these decisions may lead to a serious mis-estimation. Results also show that mandatory postponing retirement creates disincentive to saving and hinders the economy. To prevent the economy from slowing down and fertility from falling, mandatory postponing retirement must be accompanied by a lower replacement ratio.
\end{abstract}

\section{Keywords}

Retirement, Fertility, Social Security, Growth

\section{Introduction}

Over the last few decades, people are getting worried about the changes posed by the burden of population aging on the working generation and eventually on the economy. With population aging, working parents choose to postpone their retirement [1] [2] [3]. With additional labor supply from the elderly, the economy grows faster. However, under Pay-As-You-Go (PAYG) social security coverage, working parents pay more social security tax for the elderly and save more for their retirement while spending less on their children [4] [5] [6] [7] [8]. The economy grows slower because of the loss of education investment. These two independent lines of literature conclude differently on the economic performance.

Figure 1 depicts impacts of population aging in OECD countries. Notice that retirement age is increasing and fertility and education investment percentage 

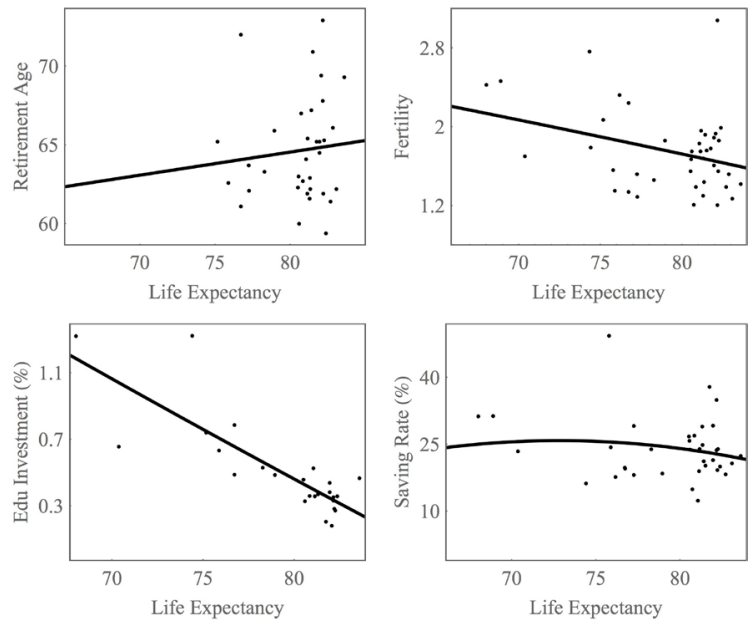

Figure 1. Population aging in OECD countries in 2014. Source: Life expectancy (Life expectancy at birth), fertility (total fertility rate), saving rate (gross saving rate as \% of GDP) from World Bank; retirement age (average effective age of retirement) and education investment (tertiary spending per student) from OECD.

are decreasing simultaneously with life expectancy. Gross saving rate presents an inverted U pattern.

Working parents make their decisions about their own retirement and intergenerational transfers simultaneously. On the one hand, population aging permits the working population to postpone their retirement and adjust the labor supply accordingly. This tends to increase lifetime income. Working parents have more financial resources available for children. On the other hand, it burdens the working population more by increasing social security tax rate. Parents tend to reduce fertility and education investment. Therefore, the overall effects on the fertility, education and, thus, economic growth, are not theoretically clear yet. For example, Mizuno and Yakita [9] endogenized fertility and showed that population aging leads to a rise in the fertility without assessments of social security and economic performance.

Constructing an Over Lapping-Generations growth (OLG) model with individuals making retirement decisions under social security coverage, this paper makes several contributions to the literature. First, this study bridges the literature of household resources allocation decisions to the literature of retirement decisions. Theoretical results show that the effects of heavier tax burden dominate the effects of postponing retirement on the fertility and economic growth when population ages. Second, the results of this study help provide a better understanding of the consequences of the retirement policies. The empirical results show that retirement decisions might be bounded by mandatory retirement policy. These results also match the theoretical predictions that mandatory late retirement policy leads to a higher fertility but a lower economic growth rate.

\section{Retirement Model}

Consider a discrete time and finite horizon OLG model with PAYG social security 
coverage and both decisions of retirement and intergenerational transfers, including fertility and education investment.

The production of the homogenous output $Y_{t}$ uses physical capital $K_{t}$ (i.e., depreciates fully after one period) and effective labor $H_{t}$ as inputs in the conventionally neoclassical fashion (Mizuno and Yakita [9]). Under perfect competition assumption, the real wage rate $w_{t}$ and the gross rate of return on physical capital $r_{t}$ are

$$
\begin{aligned}
& w_{t}=(1-\alpha) A k_{t}^{\alpha} \\
& 1+r_{t}=\alpha A k_{t}^{\alpha-1}
\end{aligned}
$$

where $k_{t}=K_{t} / H_{c t}$ represents physical capital per effective labor, $A>0$ total factor productivity and $\alpha \in(0,1)$ the share of $K_{t}$ to $Y_{t}$.

There are a large number of homogenous working parents, school-aged young children, and retired grandparents in this model economy. Since our main focus is on the population aging in relatively advanced economies, the survival rate is $100 \%$ from children to parents and is $p \in(0,1)$ from parents to grandparents. A parent of generation $\mathrm{t}$ decides his current consumption $c_{t}$ his retirement consumption $d_{t+1}$, number of identical children $n_{t}$, children's human capital level $h_{t+1}$, and the amount of time in working when old $l_{t+1} \in(0,1)$. His expected lifetime utility is

$$
u_{t}=\ln c_{t}+p \sigma_{1} \ln d_{t+1}+\sigma_{2} \ln n_{t} h_{t+1}+p \sigma_{3} \ln \left(1-l_{t+1}\right)
$$

where $\sigma_{1}, \sigma_{2}$ and $\sigma_{3}$ denote the tastes toward the retirement consumption, children, and leisure time when old, respectively. A child of generation $t+1 \mathrm{ob}-$ tains education investment $e_{t}$ from his parent and spends all his childhood in learning. He accumulates human capital according to $h_{t+1}=B e_{t}^{\beta} h_{t}^{1-\beta} . B$ denotes the productivity of learning process and $\beta \in(0,1)$ the elasticity of human capital accumulation with respect to education investment. The conventional assumptions of diminishing returns to scale in $e_{t}$ and constant returns to scale in both et and $h_{t}$ are applied here.

A working parent with 1 unit of time endowment considers sacrificing $\delta$ fraction of time raising each child, earning labor wage at $w_{t}$ paying social security tax at $\tau_{t} \in(0,1)$, saving for his own old age consumption, and investing children's education. His budget constraints are

$$
\begin{gathered}
S_{t}=\left(1-\tau_{t}\right)\left(1-\delta n_{t}\right) w_{t} h_{t}-c_{t}-e_{t} n_{t} \\
d_{t+1}=\frac{\left(1+r_{t+1}\right) s_{t}}{p}+w_{t+1} l_{t+1} h_{t}\left(1-\tau_{t+1}\right)+M_{t+1}
\end{gathered}
$$

where $M_{t+1}$ denotes the amount of social security benefit and working parents participate in the actuarially fair type of saving.

This working parent maximizes Equation (3) subject to (4) and (5). His optimal decisions are

$$
c_{t}=\frac{\left(1+r_{t+1}\right)\left(1-\tau_{t}\right) w_{t} h_{t}+p\left(1+\tau_{t+1}\right) w_{t+1} h_{t}+p M_{t+1}}{\left(1+r_{t+1}\right)\left(1+p \sigma_{1}+\sigma_{2}+p \sigma_{3}\right)}
$$




$$
\begin{gathered}
d_{t+1}=\sigma_{1}\left(1+r_{t+1}\right) c_{t} \\
n_{t}=\frac{(1-\beta) \sigma_{2} c_{t}}{\left(1-\tau_{t}\right) \delta w_{t} h_{t}} \\
e_{t}=\frac{\beta\left(1-\tau_{t}\right) \delta w_{t} h_{t}}{1-\beta} \\
l_{t+1}=\left(1-\tau_{t+1}\right) w_{t+1} h_{t}-\sigma_{3}\left(1+r_{t+1}\right) c_{t}
\end{gathered}
$$

Let $L_{t}$ denote the population of generation $t$. In a balanced PAYG system, tax revenue equals to benefits such that

$$
p L_{t} M_{t+1}=\tau_{t+1}\left[p L_{t} w_{t+1} h_{t} l_{t+1}+L_{t+1} w_{t+1} h_{t+1}\left(1-\delta n_{t+1}\right)\right]
$$

Equation (11) can be rearranged to show that tax rate equals to the replacement ratio a multiplied by the elderly support ratio.

$$
\tau_{t+1}=\frac{M_{t+1}}{w_{t+1} h_{t+1}\left[\left(1-\delta n_{t+1}\right)+\frac{p L_{t} h_{t} l_{t+1}}{L_{t+1} h_{t+1}}\right]} * \frac{p L_{t}}{L_{t+1}}
$$

Or $\tau_{t+1}=p a / n_{t}$. Tax rate is proportional to the survival rate and replacement ratio. Higher fertility relieves the tax burden because more workers share it.

Substituting Equations (1) and (2) into (11), we have

$$
p L_{t} M_{t+1}=\tau_{t+1}\left(\frac{1-\alpha}{\alpha}\right)\left(1+r_{t+1}\right) K_{t+1}
$$

Combining Equations (1) and (2), $K_{t+1}=L_{t} s_{t}$, and the last equation, we have

$$
M_{t+1}=\frac{\tau_{t+1}(1-\alpha)\left(1+r_{t+1}\right) s_{t}}{p \alpha}
$$

Due to the complexity of the retirement model, this study concentrates on the BGP equilibrium. There are three markets in the model economy-physical capital, labor, and output markets. Equation (5), (6), (7) and (10) can be used to solve for the optimal saving.

$$
s_{t}=\frac{p \alpha\left[\left(\sigma_{1}+\sigma_{2}\right)\left(1-\tau_{t}\right)\left(1+r_{t+1}\right) w_{t} h_{t}-\left(1+\sigma_{2}\right)\left(1-\tau_{t+1}\right) w_{t+1} h_{t}\right]}{\left(1+r_{t+1}\right)\left[\alpha\left(1+p \sigma_{1}+\sigma_{2}+p \sigma_{3}\right)+\tau_{t+1}(1-\alpha)\left(1+\sigma_{2}\right)\right]}
$$

On the BGP, $k, n$, and 1 are constant over time (Chen and Fang, 2013). Substituting (1), (2), (6), (13) and (14) into (8), BGP fertility is

$$
n=\frac{(1-\beta) \sigma_{2}[\alpha(1+r+p)+\tau(1-\alpha)(1+r)]}{\delta(1+r)\left[\tau(1-\alpha)\left(1+\sigma_{2}\right)+\alpha\left(1+p \sigma_{1}+\sigma_{2}+p \sigma_{3}\right)\right]}
$$

Bringing $K_{t+1}=L_{t} s_{t}, h_{t+1}=h_{t}$ and (14) into $k_{t+1}$, BGP $k$ becomes

$$
k=\frac{p \alpha w\left[\left(\sigma_{1}+\sigma_{3}\right)(1+\tau)(1+r)-\left(1+\sigma_{2}\right)(1-\tau)\right]}{(1+r)[n \gamma(1-\delta n)+p l]\left[\alpha\left(1+p \alpha_{1}+\sigma_{2}+p \sigma_{3}\right)+\tau(1-\alpha)\left(1+\sigma_{2}\right)\right]}
$$

Replacing Equation (10) with (6), (13), and (14), BGP $l$ is

$$
l=1-\frac{\sigma_{3}[\alpha(1+r+p)+\tau(1-\alpha)(1+r)]}{\alpha\left(1+p \sigma_{1}+\sigma_{2}+p \sigma_{3}\right)+\tau(1-\alpha)\left(1+\sigma_{2}\right)}
$$


Equations (15), (16), and (17) form a system of equations that gives the solutions of $n, k$, and $l$ on the BGP. Finally, $\gamma$ is

$$
\gamma=B \beta^{\beta}(1-\beta)^{-\beta}(1-\tau)^{\beta} \delta^{\beta} A^{\beta}(1-\alpha)^{\beta} k^{\alpha \beta}
$$

\section{Quantitative Analysis}

Three different scenarios are simulated in this section. At 66 denotes the scenario of mandatory late retirement at the age of 66, after 60 the scenario of self-selection fashion of retirement age and at 60 the one without the elderly labor supply. This model calibrates at 60 to fit post-war US economy. Table 1 reports these calibrated values.

\subsection{Life Expectancy}

Figure 2 depicts the situation when life expectancy prolongs from 60 to 90 . Retirees demand more social security benefit and put more tax burden on the working population. Equations (6) and (8) indicate that fertility depends upon labor income and social security benefit. On the one hand, an increase in tax rate lowers labor income after tax and suppresses fertility. On the other hand, an increase in social security benefit leads to a higher income after retirement. Working parents can afford to raise more children. The former dominates the latter and fertility declines. A prolonged life expectancy also forces working parents to save more for their retirement. Because of less labor income after tax and higher fertility, parents invest less in education. Consequently, the economic growth rate presents an inverted $u$ shape.

Comparing after 60 to at 60 , working parents choose to delay their retirement in an aging economy. This increases labor supply and reduces the tax rate.

Table 1. Variable definition and its value.

\begin{tabular}{ccc}
\hline Variable & Definition & Value \\
\hline$p d$ & Period of time (years) & 30 \\
$p$ & Survival rate & 0.6 \\
$a$ & Income replacement ratio & 0.4 \\
$\delta$ & Fraction of time raising a child & 0.15 \\
$\beta$ & Elasticity of human capital accumulation & 0.2 \\
$\alpha$ & with respect to education investment & 0.3 \\
$\sigma_{1}$ & Share of capital income to total income & 1 \\
$\sigma_{3}$ & Taste toward retirement consumption & 0.36 \\
$k$ & Taste toward leisure when old & 1 \\
$\sigma_{2}$ & Physical capital per effective labor & 0.36 \\
$A$ & Taste toward children & 13.27 \\
$B$ & Total productivity & 2.35 \\
\hline
\end{tabular}



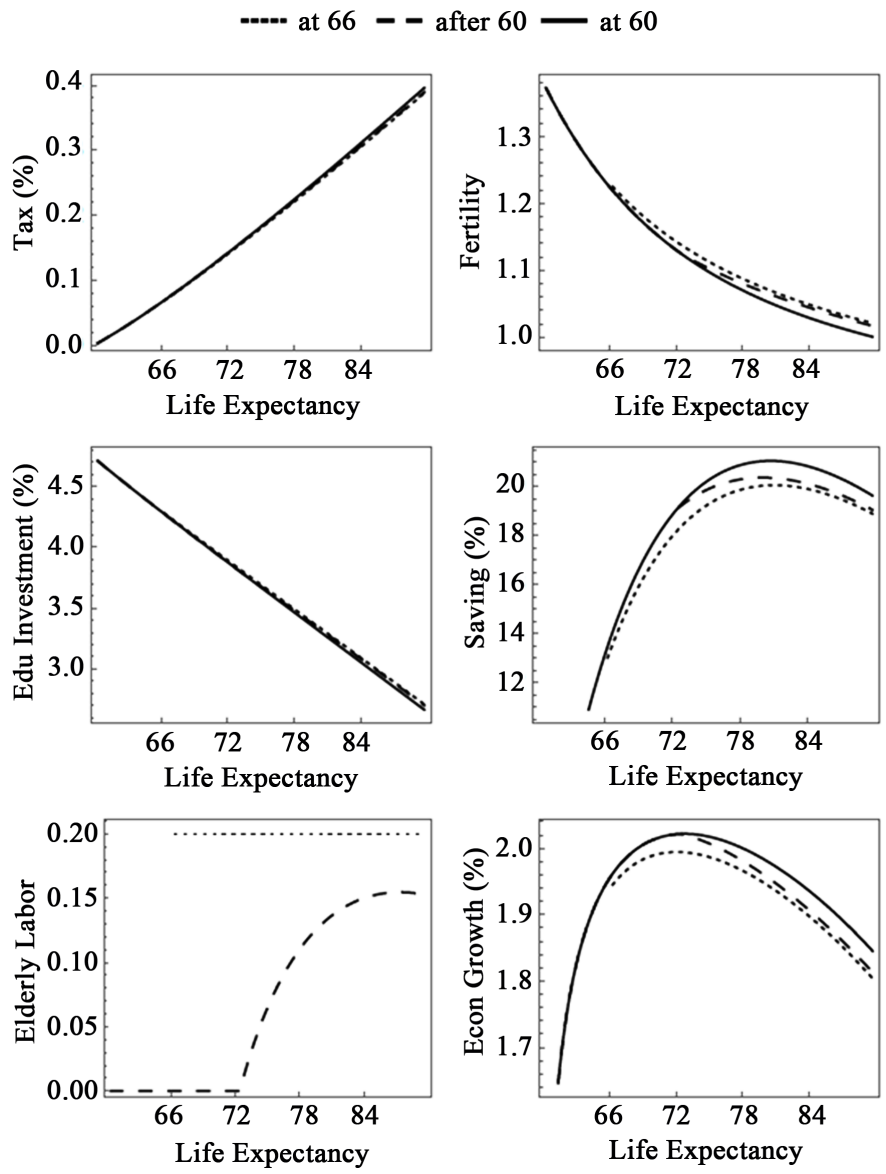

Figure 2. Impacts of life expectancy.

Because working parents expect to have additional labor income when old besides more social security benefit, they don't need to save as much for their own retirement. Fertility and education investment increase. Although more labor is supplied, less saving slows down the economy under after 60 . Therefore, the model without endogenous retirement tends to over-estimate the economic performance.

Facing population aging, the public often advocates postponing retirement due to labor shortage. Comparing at 66 to after 60 , the elderly supply more labor and tax rate is lower. Working parents choose to raise fertility and education investment while saving less. The economy grows slower under at 66 . On the contrary, rather than postponing retirement, mandatory early retirement, at 60 , creates incentive to save more and promotes the economy.

In the empirical evidence section, this study verifies that at 66 is more aligned to real world economy than after 60 and at 60 in that personal decisions toward retirement are often bounded by policy. The empirical results also support our theoretical predictions of decreasing rates of fertility and economic growth due to population aging. Therefore, the effects of longer working time and higher lifetime income are dominated by the effects of heavier tax burden due to population aging as predicted by the theoretical model. 


\subsection{Replacement Ratio}

Figure 3 shows the situation that the replacement ratio increases from 0 to 1 . Working parents need to pay more for the social security and earn less labor income after tax. This tends to demote fertility. Meanwhile, more social security benefit promotes fertility. This time, the latter dominates the former. Fertility increases while education investment decreasing. More social security benefit also means working parents might save less. Consequently, the economy grows slower.

Comparing after 60 to at 60 , working parents decide to supply labor when old as long as the replacement ratio is below 0.55. With additional labor supply when old, tax rate drops and labor income after tax increases. Both fertility and education investment increase. Parents also don't need to save as much and the economy grows slower. Again, the model without endogenous retirement tends to over-estimate the economic performance.

Comparing at 66 to after 60 , when the replacement ratio lies between 0.27 and 0.55 , the middle range, the elderly supply more labor. Lower tax rate allows parents to choose higher fertility and education investment. Lowered saving because of more labor supply when old hinders the economy. The original purpose of mandatory late retirement is to increase labor supply when population ages
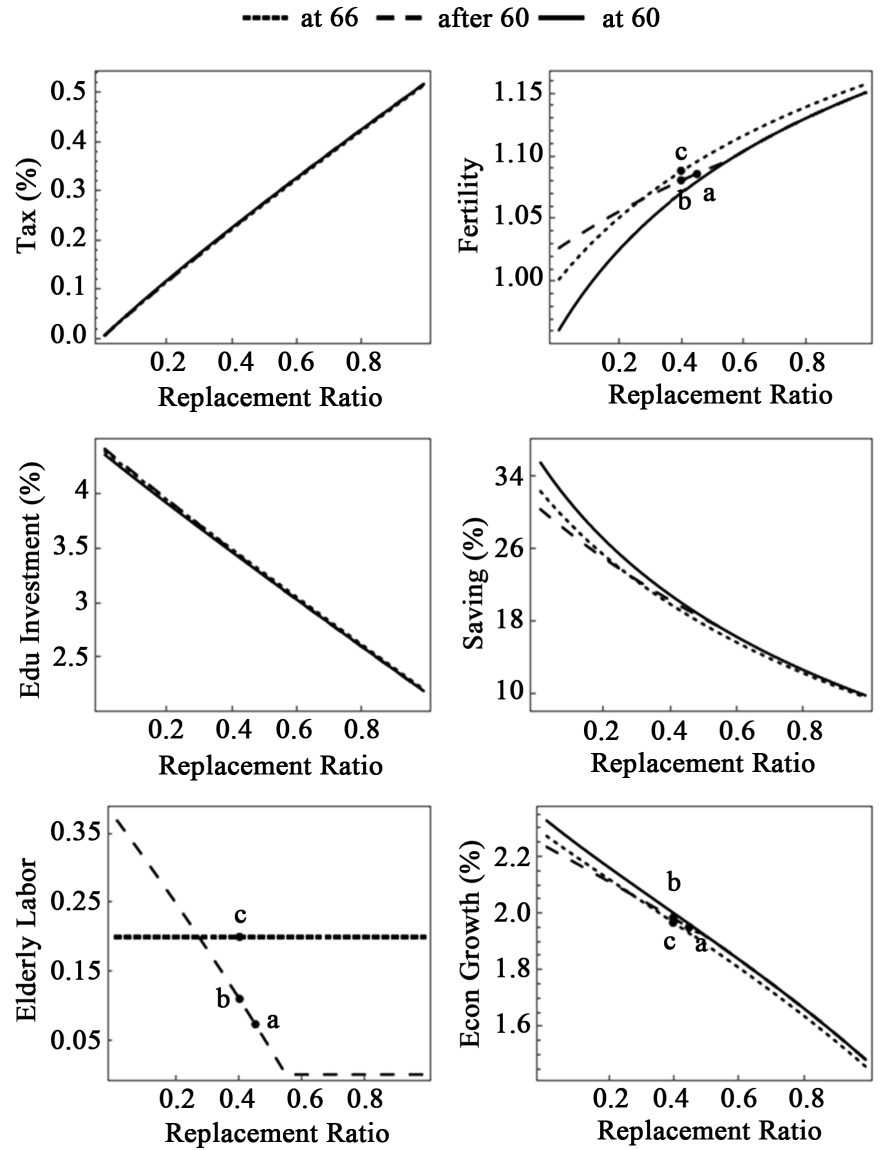

Figure 3. Impacts of replacement ratio. 
and labor shortage presents. However, it may not serve as a growth enhancer alone within reasonable range of replacement ratio. A reduction in the replacement ratio may. Furthermore, the elderly supply more labor with a reduction of replacement ratio. A move from points a to $\mathrm{b}$ presents this situation.

However, if low fertility is also under the spotlight, the replacement ratio reduction makes fertility rate even lower. For example, a move from point a to point $b$ along the fertility curve under after 60 . It's a trade-off between the elderly labor supply and future-generation labor supply. To maintain economic growth and fertility, a mandatory late retirement paired with a replacement ratio reduction moves the economy from point a to point $c$. As a bonus, the elderly supply more labor.

\section{Empirical Evidence}

There are several theoretical results that draw our attentions. First, although replacement ratio and life expectancy influent optimal decisions about retirement age, it might be also bounded by the mandatory retirement policy. Second, the delay of retirement age increases fertility, holding life expectancy constant. Third, if the retirement age is bounded to the policy, the economic growth should be negatively related to retirement age. In this section, the empirical relevancy of these relationships is assessed.

This study employs data acquired from the OECD and World Bank. To support theoretical findings without distracting the attention, variables are kept to a minimum. Average effective age of retirement (Retirement) is the average age of exit from the labor force during 2009-2014. Normal retirement age (Normal) is the age at which an individual can retire in 2014 without any reduction to their pension. The men net pension replacement rate (Replacement) is the individual net pension entitlement divided by net pre-retirement earnings in 2014. These key variables are not widely available in time-series format and exhibit very high inertia from year to year. These two reasons may justify our use of cross sectional data. Finally, general government spending (Govspd) in 2014 and government expenditure on education as \% of GDP in 2014 (Pubedu) are introduced to control for the omitted variables. The regression results are as Table 2 .

Retirement equation shows a negative and significant correlation between retirement age and replacement ratio and a positive and significant relationship between retirement age and normal retirement age. The correlation between retirement age and life expectancy is insignificant but the one between retirement age and normal retirement age is positive and significant. This suggests that personal retirement decisions might be more or less bounded by governmental regulations. A study of population aging without considering mandatory retirement might cause estimation error.

Population aging increases lifetime income and children. Population aging also puts heavier burden on parents and reduces fertility. The empirical results support the model prediction that the latter effect dominates the former. Fertility 
Table 2. Regressions results.

\begin{tabular}{ccccccc}
\hline \multirow{2}{*}{ Variables } & \multicolumn{2}{c}{ Retirement } & \multicolumn{2}{c}{ Fertility } & \multicolumn{2}{c}{ Growth } \\
\cline { 2 - 7 } & Coef. & Std. Dev. & Coef. & Std. Dev. & Coef. & Std. Dev. \\
\hline Intercept & $37.707^{* *}$ & 19.005 & $159.363^{* * *}$ & 60.978 & $507.048^{* *}$ & 255.546 \\
Replacement & $-0.045^{*}$ & 0.0234 & & & & \\
Life & -0.199 & 0.208 & & & & \\
Normal & $0.712^{* *}$ & 0.217 & & & & \\
Retirement & & & $-4.997^{* * *}$ & 1.91 & $-16.103^{* *}$ & 7.071 \\
Retairement & & & $0.394^{* * *}$ & 0.015 & $0.127^{* * *}$ & 0.055 \\
Pubedu & & & $0.083^{* * *}$ & 0.052 & & \\
GDP & & & & & $-0.335^{* * *}$ & 0.009 \\
Govspd & & & & & $0.470^{* * *}$ & 0.103 \\
$\mathrm{R}^{2}$ & 0.397 & & 0.291 & & 0.527 & \\
\hline
\end{tabular}

Note: Life represents life expectancy. ${ }^{* * *},{ }^{* *}$, and ${ }^{\star}$ donate significance at $1 \%, 5 \%$, and $10 \%$ level, respectively.

equation shows a negative and significant correlation between fertility and retirement age and a positive and significant correlation between fertility and retirement age squared. Therefore, when the retirement age is greater than 12.7, retirement age increases fertility holding others constant. This result confirms the upper-right panel of Figure 2 that when holding life expectancy at a given level, higher retirement age (ex. at 66 compared to at 60 ) is associated with a higher fertility.

Growth equation shows a negatively significant correlation between economic growth rate and retirement age and positively significant one between economic growth and retirement age in quadratic form. Thus, when the retirement age is less than 126.8, retirement age decreases economic growth holding others constant. This result supports the lower-right panel of Figure 2 that when holding life expectancy at a given level, higher retirement age is associated with a lower economic growth rate.

These results support our mandatory retirement model and its predictions that mandatory late retirement improves fertility but depresses economic growth. Therefore, population aging researches should pay more attentions to the effects of mandatory retirement than simply the effects of life expectancy and replacement ratio.

\section{Conclusions}

This paper presents an OLG model with both retirement and fertility decisions endogenized to study population aging and social security. Population aging allows working parents to postpone their retirement and shift more resource toward children. It also puts more social security burden on working parents. They have less resource available for the children. The results show that failing to account for either one of these two simultaneously opposite forces on the fertility 
may lead to a seriously mis-estimation of the economic performance.

The results also show that, rather than postponing retirement, mandatory early retirement creates incentive to save more and promotes the economy. Since labor shortage is on the center stage of policy making nowadays, postponing retirement age is a consensus and a popular policy. It is well-known that sometimes competitive market solutions deviate from the ones socially planned especially in the OLG models [10]. It is also well-known that unfounded social security (PAYG) reduces saving and leads to Pareto improvements [11]. In this study, a mandatory postponing retirement policy shifts fertility up. Because consumption is positively related to fertility and lifetime utility in the model, this postponing retirement policy leads to Pareto improvements. Therefore, it is justifiable to postpone retirement age when over accumulation occurs. For the postponing retirement policy to work as the growth enhancer, the accomplishment of replacement ratio reduction is a must especially when the government intends to maintain high fertility. Due to the limitation of data quality, this study employs cross-sectional data from OECD and World Bank. Further research can use pooled cross sections data when available to closely examine the consequences of changes in retirement policies.

\section{Conflicts of Interest}

The authors declare no conflicts of interest regarding the publication of this paper.

\section{References}

[1] Hu, S.C. (1979) Social Security, the Supply of Labor, and Capital Accumulation. American Economic Review, 69, 274-283.

[2] Echevarria, C.A. (2004) Life Expectancy, Schooling Time, Retirement, and Growth. Economic Inquiry, 42, 602-617. https://doi.org/10.1093/ei/cbh084

[3] Echevarria, C.A. and Iza, A. (2006) Life Expectancy, Human Capital, Social Security and Growth. Journal of Public Economics, 90, 2323-2349.

https://doi.org/10.1016/j.jpubeco.2006.07.001

[4] Pecchenino, R.A. and Utendorf, K.R. (1999) Social Security, Social Welfare and the Aging Population. Journal of Population Economics, 12, 607-623. https://doi.org/10.1007/s001480050116

[5] Kaganovich, M. and Zilcha, I. (1999) Education, Social Security, and Growth. Journal of Public Economics, 71, 289-309. https://doi.org/10.1016/S0047-2727(98)00073-5

[6] Tosun, M.S. (2003) Population Aging and Economic Growth: Political Economy and Open Economy Effects. Economics Letters, 81, 291-296. https://doi.org/10.1016/S0165-1765(03)00195-2

[7] Ludwig, A. and Vogel, E. (2010) Mortality, Fertility, Education and Capital Accumulation in a Simple OLG Economy. Journal of Population Economics, 23, 703-735. https://doi.org/10.1007/s00148-009-0261-8

[8] Chen, H.-J. and Fang, I.-H. (2013) Migration, Social Security, and Economic Growth. Economic Modelling, 32, 386-399.

https://doi.org/10.1016/j.econmod.2013.02.026 
[9] Mizuno, M. and Yakita, A. (2013) Elderly Labor Supply and Fertility Decisions in Aging-Population Economies. Economics Letters, 121, 395-399.

https://doi.org/10.1016/j.econlet.2013.09.022

[10] de la Croix, D. and Michel, P. (2002) A theory of Economic Growth: Dynamics and Policy in Overlapping Generations. Cambridge; New York and Melbourne.

[11] Acemoglu, D. (2009) Introduction to Modern Economic Growth. Princeton and New York. 